\title{
VIGOTSKI E PSICOLOGIA DA ARTE: HORIZONTES PARA A EDUCAÇÃO MUSICAL
}

\author{
Maria Flávia Silveira Barbosa ${ }^{1}$ (D)
}

\begin{abstract}
RESUMO: Este texto é resultado de estudos que integram uma pesquisa mais ampla acerca da importância da arte na formação dos indivíduos, cujo referencial teórico é o materialismo histórico e dialético. $\mathrm{O}$ recorte que aqui se apresenta trata da concepção de catarse na obra de Vigotski e suas possíveis implicaçóes para o ensino de música, na escola. Partindo da concepção de catarse como fundamento, busca-se lançar luz sobre questôes do campo didático-metodológico, tais como: qual o papel da música na formação do indivíduo? Quais conteúdos musicais devem ser trabalhados? Como devem ser trabalhados?
\end{abstract}

Palavras-chave: Lev Vigotski. Psicologia da arte. Catarse. Música. Educação musical.

\section{Vygotsky and Psychology of Art: horizons for music education}

\begin{abstract}
This text is the result of studies that integrate a broader research on the importance of art in the formation of individuals, whose theoretical reference is historical and dialectical materialism. The present section deals with the conception of catharsis in Vygotsky's work and its possible implications for music-teaching at school. Starting from the
\end{abstract}

\footnotetext{
${ }^{1}$ Universidade Federal de Uberlândia, Instituto de Artes, Programa de Pós-Graduação em Música - Uberlândia (MG), Brasil. E-mail: mariaflavia@usp.br

DOI: $10.1590 /$ CC0101-32622019213310
} 
conception of catharsis as a foundation, it is sought to shed light on questions of the didactic-methodological field, such as: what is the role of music in the formation of the individual? What musical content should be worked on? How should they be worked?

Keywords: Lev Vygotsky. Psychology of art. Catharsis. Music. Music education.

\section{INTRODUÇÃO}

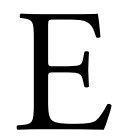

ducadores musicais brasileiros têm adotado em seus trabalhos as concepçóes do autor russo Lev Vigotski como zona de desenvolvimento iminente, papel do signo e do outro na constituição do psiquismo, entre outras ${ }^{1}$. Entretanto, a concepçáo de arte do referido autor merece ainda ser mais amplamente considerada ${ }^{2}$. De minha parte, acredito nas contribuições que podem advir dessa concepção para o campo da educação musical, tanto em seus fundamentos teóricos como em seus desdobramentos didático-metodológicos.

O objetivo deste texto pode ser, então, formulado: toma-se como fundamento a concepção de arte elaborada por Vigotski, buscando elucidar questóes do campo didático-metodológico em educação musical: qual o papel da música na formação do indivíduo? Quais conteúdos musicais devem ser trabalhados nas escolas regulares? Como devem ser trabalhados esses conteúdos?

Já há algum tempo tenho buscado respostas para essas questóes por observar uma falta de clareza a respeito do lugar da música na educaçáo básica; o que conduz a práticas pedagógicas de muito baixo impacto na formação de crianças e jovens brasileiros. Incomoda-me, particularmente, o fato recorrente de que os profissionais da área, mesmo quando pretendem encontrar uma resposta "científica" para esse problema, com frequência tropeçam em justificativas que não vão além do uso instrumental da música a favor de outros componentes curriculares; e, nesses casos, as questóes propriamente musicais acabam ficando em segundo 
plano. Foi na teoria vigotskiana e também nas formulaçôes de Dermeval Saviani, em sua pedagogia histórico-crítica ${ }^{3}$, que encontrei as respostas mais coerentes e, com base nesse referencial, tenho fundamentado minhas reflexōes e práticas.

Só recentemente, chamou-me a atenção a concepção de arte elaborada por Vigotski; já publiquei alguns estudos apontando as suas contribuiçôes para a superaçấo de preconceitos arraigados no campo da arte, como a questấo do dom ou talento inato e estabelecendo também algumas diretrizes didático-metodológicas a partir desse fundamento ${ }^{4}$. Mas a minha intenção aqui é aprofundar o entendimento dessa concepção de arte, porque considero que em meus trabalhos anteriores náo foram atingidas questôes cruciais que podem lançar nova luz sobre as práticas em educação musical ${ }^{5}$.

Quanto à organização da estrutura deste trabalho, considerei importante apresentar, inicialmente, mesmo que de modo breve, a concepção formulada por Vigotski (1998) em seu livro Psicologia da arte. Em seguida, estabeleci elos com a educaçáo musical, destacando os aspectos da concepção vigotskiana de arte que podem fundamentar reflexões e práticas mais promissoras e apresentando, em caráter preliminar, algumas elaboraçôes didático-metodológicas para o ensino de música, sobretudo em escolas regulares.

\section{VIGOTSKI E PSICOLOGIA DA ARTE}

Em seu livro intitulado Psicologia da arte ${ }^{6}$, Vigotski (1998) propõe-se a superar o subjetivismo em direção ao objetivismo, no estudo das artes e da psicologia; busca, nesse sentido, formular o problema da arte, propor um método de estudo e o "princípio psicológico básico da explicação" (VIGOTSKI, 1998, p. 2), sob premissas objetivas. Afirma: "Achamos que a idéia central da psicologia da arte é o reconhecimento da superação do material da forma artística ou, o que dá no mesmo, o reconhecimento da arte como técnica social do sentimento" (VIGOTSKI, 1998, p. 3, grifo do autor). Esse excerto, em minha opinião, dá a dimensão da tentativa de Vigotski de superar o subjetivismo no entendimento de questóes de arte. Assumindo o marxismo como fundamento de suas 
elaboraçóes, o autor propóe um método de estudo da forma e do material da arte; isso é bastante diferente de elaborar uma psicologia do autor ou do leitor (ou espectador). Em outras palavras, Vigotski não toma como dado para as suas elaboraçóes as impressóes, depoimentos etc. de autores ou leitores das obras que analisa - essa seria, claramente, uma abordagem subjetivista. Por outro lado, toma como objeto de análise a obra de arte, "pesquisando apenas [sua] forma e [seu] material" (VIGOTSKI, 1998, p. 3). E é na análise do conteúdo e da forma da obra de arte que o autor encontra a natureza contraditória que promove a reação estética, a catarse, como tentarei mostrar a seguir.

$\mathrm{Na}$ obra em tela, nosso autor trata de várias questóes concernentes a arte, estética e psicologia; e polemiza com autores desses campos, representantes dos mais diferentes matizes teóricos, para elaborar a sua teoria da reação estética. Há um longo capítulo metodológico; três capítulos em que apresenta e se opóe a certas concepçóes de arte - a saber, arte como conhecimento, arte como procedimento e a perspectiva psicanalítica da arte; em seguida, expóe suas análises de fábulas, de uma novela (Leve alento, de Ivan Búnin) e de uma tragédia (Hamlet, de Shakespeare), construindo os argumentos para a concepçáo de arte como catarse, que vai aparecer sobretudo nos capítulos 9 e 10 (capítulos de síntese); por fim, tendo chegado a uma ideia original acerca da reação estética, indaga-se sobre o significado da arte no interior mesmo de suas reflexóes e quer saber quais relaçóes são estabelecidas entre a arte (entendida como catarse) e o conjunto da vida social humana. Não será possível apresentar aqui, em razão da extensão deste trabalho, mais do que as formulaçóes gerais da concepção vigotskiana, mas acredito que bastará para o meu propósito.

"A arte como catarse" é o título do capítulo em que Vigotski afirma, referindo-se ao material por ele analisado: "o exame dos estudos anteriores nos mostrou que toda obra de arte — fábula, novela, tragédia - encerra forçosamente uma contradição emocional, suscita séries de sentimentos opostos entre si e provoca seu curto-circuito e destruição" (VIGOTSKI, 1998, p. 269). Vejamos um exemplo: na análise da novela Leve alento, de Ivan Búnin, Vigotski observa que o conteúdo, ou material, não é apresentado ao leitor de forma linear; pelo contrário, é justamente "a disposição artificial dos acontecimentos que os transfor- 
ma em enredo artístico e recua da sequência cronológica” (VIGOTSKI, 1998, p. 180) - a sequência cronológica pode ser simbolizada por uma linha e a apresentação dos acontecimentos na obra, por uma ou mais curvas (saltos adiante e para trás); tais curvas e saltos transgridem totalmente a ordem cronológica e essa transgressão dá origem à forma artística. Em vez de apresentar os acontecimentos cronologicamente, Búnin os "enforma” de maneira totalmente deslocada e, de acordo com a análise de Vigotski, esse reordenamento e o modo como Búnin apresenta os acontecimentos transforma "água em vinho como sempre o faz a obra de arte" (VIGOTSKI, 1998, p. 191). A esse processo, chama "lei da destruição do conteúdo pela forma" (VIGOTSKI, 1998, p. 193). Nosso autor finaliza a análise da novela afirmando ter descoberto: "que a forma combate o conteúdo, luta com ele, supera-o, e que nessa contradição dialética entre conteúdo e forma parece resumir-se o verdadeiro sentido psicológico da nossa reação estética” (VIGOTSKI, 1998, p. 199).

Nesse ponto, Vigotski traz o conceito de catarse, formulado, primeiramente, por Aristóteles. Apesar da dificuldade de precisar o significado de catarse, tanto em Aristóteles como em outros autores que desse termo se apropriaram ao longo da história, o autor russo entende ser o melhor para explicar "o verdadeiro efeito da obra de arte" (VIGOTSKI, 1998, p. 269), pois, somente ele

traduz com tanta plenitude e clareza o fato, central para a reaçáo estética, de que as emoçóes angustiantes e desagradáveis são submetidas a certa descarga, à sua destruição e transformação em contrários, e de que a reaçáo estética como tal se reduz, no fundo, a essa catarse, ou seja, à complexa transformação dos sentimentos (VIGOTSKI, 1998, p. 270).

Adiante, afirma que "a base desse processo é a natureza contraditória que subjaz à estrutura de toda obra de arte" (VIGOTSKI, 1998, p. 270). Há emoçóes que são suscitadas pelo material e há emoçóes que são suscitadas pela forma; e elas estão sempre "em permanente antagonismo", "direcionadas em sentidos opostos" (VIGOTSKI, 1998, p. 270), de modo que Vigotski assim formula: "da fábula à tragédia a lei da reação 
estética é uma só: encerra em si a emoção que se desenvolve em dois sentidos opostos e encontra destruição no ponto culminante, como uma espécie de curto-circuito" (VIGOTSKI, 1998, p. 270, grifo do autor). Nesse confronto de emoçóes contraditórias, o conteúdo é sempre destruído pela forma.

Vigotski resume, então:

É nessa unidade de sentimento e fantasia que se baseia qualquer arte. Sua peculiaridade imediata consiste em que, ao nos suscitar emoções voltadas para sentidos opostos, só pelo princípio da antítese retém a expressão motora das emoçôes e, ao pôr em choque impulsos contraditórios, destrói as emoçóes do conteúdo, [e] as emoçôes da forma, acarretando a explosão e descarga da energia nervosa. // É nessa transformação das emoçóes, nessa autocombustáo, nessa reação explosiva que acarreta a descarga das emoçóes imediatamente suscitadas, que consiste a catarse da reação estética (VIGOTSKI, 1998, p. 272).

No capítulo intitulado "Arte e vida", Vigotski opóe-se à teoria de Léon Tolstói, segundo a qual a arte se fundamenta no contágio do receptor pelos sentimentos do autor. Afirma que, sendo assim, o sentimento produzido pela arte não teria nenhuma especificidade em relação a outros sentimentos; sua função seria, tão somente, a de um amplificador ou transmissor no contágio dos sentimentos. Argumenta:

Em realidade, como seria desolador o problema da arte na vida se ela não tivesse outro fim senão o de contagiar outras pessoas com o sentimento de uma. Seu significado e seu papel seriam extremamente insignificantes, porque em arte acabaríamos sem ter qualquer outra saída desses limites do sentimento único, exceto a ampliação quantitativa desse sentimento. Neste caso o milagre da arte lembraria o desolador milagre do Evangelho, em que cinco ou seis pães e uma dúzia de peixes alimentam mil pessoas, todas comem até saciar a fome e os ossos restantes são recolhidos em doze cestas. Aqui o milagre é apenas quantitativo: mil pessoas que 
se saciaram, mas cada uma comeu apenas peixe e páo, pão e peixe. Não seria isto o mesmo que cada uma delas comia cada dia em sua casa, sem qualquer milagre? (VIGOTSKI, 1998, p. 307).

Para o nosso autor, ao contrário, a arte tem que ver com transformação qualitativa dos sentimentos e mais se assemelha a outro milagre evangélico — o da transformação da água em vinho: "a verdadeira natureza da arte sempre implica algo que transforma, que supera o sentimento comum, e aquele mesmo medo, aquela mesma dor, aquela mesma inquietação, quando suscitadas pela arte, implicam o algo a mais acima daquilo que nelas está contido” (VIGOTSKI, 1998, p. 307). $\mathrm{E}$, aprofundando a comparaçáo com o milagre, afirma que, assim como o vinho é feito da uva, mas é bastante diferente de sua matéria-prima, a arte toma da vida seu material (seu conteúdo), mas o transforma em algo "acima desse material algo que ainda não está nas propriedades desse material” (VIGOTSKI, 1998, p. 308).

\section{A PSICOLOGIA DA ARTE DE VIGOTSKI COMO FUNDAMENTO PARA REFLEXÕES E PRÁTICAS EM EDUCAÇÃO MUSICAL}

Começarei com as implicaçóes que vejo a partir da própria concepçáo sintetizada anteriormente e, a seguir, destacarei algumas formulações de Vigotski que aparecem ao longo de seu texto e que estão implicadas na concepção por ele postulada. Naturalmente, faço isso com muita cautela; tendo em mente que Vigotski está elaborando uma teoria da reação estética e aqui se trata de pensar a educação musical; assim, as suas formulaçóes sofrerão sempre a mediação das questóes próprias do trabalho pedagógico.

A ideia de catarse, entendida como transformação qualitativa dos sentimentos, aponta, a meu ver, para a importância da arte/música na formação dos indivíduos. É forçoso voltar a um velho e surrado dilema: o lugar da música na educação escolar tem sido ainda, lamentavelmente, o de entretenimento ou apoio a outras disciplinas. Ora, se a arte deve provocar "transformação qualitativa de sentimentos", então, 
os conteúdos trabalhados e o modo como se deve trabalhá-los devem ser outros. Em aulas de música, não ensaiar para apresentaçóes ou para o teatro das disciplinas de história ou língua portuguesa, mas trabalhar com o objetivo de promover catarses!

Em seu capítulo metodológico (VIGOTSKI, 1998, p. 7-27), Vigotski apresenta o método por ele trabalhado na análise de obras de arte, em contraposição às ideias prevalentes em seu tempo. Propóe, entâo, o método analítico objetivo para seus estudos: tomar por base a obra de arte e não as emoçóes ou sentidos produzidos pelos artistas ou pelos fruidores. Acredito que essa proposta metodológica pode servir como diretriz para pensarmos os conteúdos a serem trabalhados em sala de aula e, também, o modo como podemos trabalhá-los. O objeto de estudo será a obra de arte em sua materialidade e não as impressóes que causa nos fruidores ou, tampouco, as intençôes do autor. $\mathrm{O}$ foco também não será, pelo menos não será só, analisar o contexto histórico em que a obra foi composta; isso é importante, mas pode deixar a obra de arte propriamente em segundo plano. No caso da música, tomar a proposta metodológica de Vigotski como diretriz significa, por exemplo, trabalhar os elementos da linguagem musical a fim de compreender a estrutura da obra ou o modo como o compositor organizou o material e a forma musical para produzir certo sentido. Isso não é o mesmo que ensinar teoria musical: primeiramente, parte-se da percepçáo auditiva das obras e, em segundo lugar, busca-se a aproximação com outras formas de linguagem, para só então formular conceitos teóricos e, finalmente, voltar à obra, agora compreendida em nível superior.

Diz o nosso autor: "A verdadeira natureza da arte sempre implica algo que transforma, que supera o sentimento comum" (VIGOTSKI, 1998, p. 307). A concepçáo de arte de Vigotski abarca, a meu ver, uma concepção sobre obra de arte. Se a reação estética é provocada pela natureza contraditória da obra de arte, ou seja, pelo modo como o artista trabalha o material/conteúdo e a forma, em sua obra, então, é possível afirmar que nosso autor esteja considerando como obra de arte elaboraçóes humanas que contenham essa riqueza (sentimentos contraditórios), que tenham o potencial de transformar e superar o sentimento comum. Permito-me trazer uma reflexão anterior: 
Nesse início de século XXI, todos os aspectos da vida social são atingidos pelas relaçóes alienadas e alienantes vividas sob a égide do capital; não é diferente em relação à arte. $\mathrm{O}$ professor que irá trabalhar com as linguagens artísticas deve ter clareza a esse respeito, tomando como critério para a seleção dos conteúdos curriculares não a arte banal, ligeira, veiculada pela mídia - pelo menos náo só. Tenho trabalhado, em educaçáo musical, com a ideia de tomar como ponto de partida as vivências musicais dos alunos, mas sempre com o compromisso de ir além delas, ampliando-as para voltar posteriormente a elas, com um olhar mais crítico e reflexivo (BARBOSA, 2017, p. 739).

Para além de preferências, diferenças culturais e muito além da simplificação popular versus erudito, é fundamental levar para as aulas de música obras que tenham o potencial de transformar sentimentos comuns; ou de reelaborar esses sentimentos em direção a uma compreensão superior (superação), como é a ideia de catarse, em Vigotski.

Nosso autor é bastante atual quando reflete sobre o sentido pedagógico da arte (VIGOTSKI, 1998, p. 321-329). Um dos problemas que trata é o da arte na educação, apontando duas vertentes das quais discorda: primeira, a que toma a arte como propaganda, ou seja, a que tenta extrair dela preceitos morais, o que empobrece tanto a obra de arte como o trabalho educativo; segunda, a que considera desnecessário o ensino de arte na escola. De acordo com Vigotski, os autores que defendem essa última ideia veem a obra de arte e o ato criador de forma mistificada, em suas palavras, veem a arte como "ato místico do espírito" (VIGOTSKI, 1998, p. 324), não passível de ser estudada ou ensinada. Atualmente, são outras as motivaçóes, mas ainda temos defensores ferrenhos da retirada da arte do currículo da educaçáo básica — será por conhecer ou desconhecer o seu potencial na formaçáo dos indivíduos? Penso que a luta de cada profissional da nossa área deve ser pela ampliação irrestrita do acesso à arte, e a escola é, até o momento, o melhor lugar para isso. Nas elaboraçóes de Vigotski, encontramos fundamento teórico para travar essa luta.

Uma das poucas formulaçóes em que nosso autor se refere especificamente à música e aos efeitos que provoca nos ouvintes é a reflexão 
a partir de um trecho da novela de Léon Tolstói, intitulada $A$ Sonata a Kreutzer (VIGOTSKI, 1998, p. 317-320). Vejamos alguns excertos: "Estimulante novo e fortíssimo para posteriores atitudes" (VIGOTSKI, 1998, p. 318, grifo meu); "A música nos sujeita a uma extrema confusáo e intranquilidade, porque desencadeia, desvela as forças integrais daquelas aspiraçôes que só podem resolver-se em atos heróicos de excepcional importância"; "o efeito da música vem a ser imensuravelmente mais sutil, mais complexo e se produz, por assim dizer, através de abalos e deformaçóes subterrâneas do nosso posicionamento" (VIGOTSKI, 1998, p. 319);

a música, por si mesma e de forma imediata, está mais isolada do nosso comportamento cotidiano, não nos leva diretamente a nada, mas cria táo somente uma necessidade imensa e vaga de agir, abre caminho e dá livre acesso a forças que mais profundamente subjazem em nós, age como terremoto, desnudando novas camadas (VIGOTSKI, 1998, p. 320).

Eis aqui explicitado o potencial catártico da música: trata-se de criação humana capaz de desenvolver consciência. A transformação qualitativa, a reelaboração dos sentimentos, a catarse, afinal, é, em minha opiniâo, elaboraçáo superior da consciência; ou seja, é forma superior de compreender a vida; a compreensão leva (sutilmente, mas leva) à açáo; e a ação é de transformação da realidade. Eis o papel da educação musical!

Para terminar este texto, deixando ainda muitas questóes para um outro momento, a bela formulação de Vigotski: "A arte é o social em nós” (VIGOTSKI, 1998, p. 315). Várias proposiçóes surgem para a educação musical, ou antes, para o ensino de arte. Sendo "o social em nós", a arte não é exteriorização de sentimentos puramente subjetivos ou manifestação de habilidades dadas a priori. Ao contrário, é desdobramento da vida conjunta dos homens, da vida em sociedade; é construção histórica, assim como, consequentemente, os sentidos necessários à sua fruição. Social é a natureza da criação e da fruição artística. Embora não tenha sido essa a discussão em pauta no texto vigotskiano, temos aqui uma ideia que se contrapóe a concepçóes que postulam dom e talento inato como condiçóes prévias para o desenvolvimento artístico. E aponta para 
a importância fundamental de um trabalho educativo que desenvolva os sentidos estéticos, sem os quais a arte não poderá cumprir a sua função de transformação qualitativa de sentimentos. Apesar de não ter conhecido o texto de K. Marx intitulado Manuscritos econômico-filosóficos, Vigotski está em consonância com a concepção marxiana:

[É] apenas pela riqueza objetivamente desdobrada da essência humana que a riqueza da sensibilidade humana subjetiva, que um ouvido musical, um olho para a beleza da forma, em suma as fruiçóes humanas todas se tornam sentidos capazes, sentidos que se confirmam como forças essenciais humanas, em parte recém-cultivadas, em parte recém-engendradas (MARX, 2010, p. 110 , grifos do autor).

Na obra de arte ("riqueza objetivamente desdobrada da essência humana”), a catarse é apenas potencial; sem a devida apropriação das linguagens artísticas (o desenvolvimento da "riqueza da sensibilidade humana subjetiva”), esse potencial não se realizará. Tal processo se dá, preferencialmente, pelo contato sistemático e organizado com obras de arte.

Sendo "o social em nós", a arte nos traz a possibilidade de vivenciar a experiência de todo o gênero humano, ao longo da história. Vejamos uma passagem, no capítulo em que Vigotski analisa Hamlet, de Shakespeare.

A tragédia pode obter esses efeitos incríveis [a catarse] sobre os nossos sentimentos precisamente porque os leva a transformar-se constantemente em seus opostos, a enganar-se em suas expectativas, a esbarrar em contradiçôes, a desdobrar-se; e quando vivemos Hamlet temos a impressão de que vivemos milhares de vidas humanas em uma noite e, de fato, conseguimos experimentar mais emoçóes do que em anos inteiros da nossa vida comum (VIGOTSKI, 1998, p. 243).

Com a arte temos, portanto, a oportunidade de superar a "nossa vida comum", compartilhando diversas e diferentes experiências humanas. 


\section{CONSIDERAÇÕES}

A proposta deste texto foi apresentar resumidamente a concepção de arte contida em Psicologia da arte, de Vigotski, e, a partir das concepçóes postuladas pelo autor russo, buscar contribuiçóes para o ensino de música, sobretudo nas escolas de educação básica. Formular proposiçôes para o campo didático-metodológico é urgente em educação musical, se quisermos garantir a sua presença nas escolas regulares presença até o momento bastante débil, em razáo das idas e vindas da legislação brasileira, mas, também, pelo baixo impacto que os fazeres nessa área têm provocado na formação dos nossos jovens e das nossas crianças. Formular proposiçóes não significa, entretanto, apresentar um "método acabado", porque acredito que métodos são construídos no processo de reflexão e prática, nunca antecipadamente.

Acredito profundamente na importância da arte para a formação de todos os indivíduos; acredito na contribuição que traz para o conhecimento da realidade humana, do passado e do presente; sem esse conhecimento, é impossível compreender o nosso lugar no mundo. Não tenho dúvida de que o livro Psicologia da arte e as ideias elaboradas por Vigotski podem, com as devidas mediaçôes, contribuir no sentido de fundamentar uma educação musical que cumpra essa função.

\section{REFERÊNCIAS}

BARBOSA, M.F. A arte na formação do indivíduo: superando preconceitos. Linhas Críticas, Brasília, v. 22, n. 49, p. 727-743, 2017.

. Educação musical infantil: uma nova proposta. Claves, João Pessoa, v. 3, p. 74-82, maio 2007.

. Inclusão escolar e ensino de arte: aproximaçóes. Olh@res, Guarulhos, v. 3, n. 1, p. 143-167, maio 2015.

. O lugar da música: em busca de elementos que respaldem a presença significativa da música na educação infantil. In: ENCONTRO ANUAL DA ABEM, 14., 2005, Belo Horizonte. Anais... Belo Horizonte, 2005, p. 1-5. 
BENEDETTI, K.S.; KERR, D.M. O papel do conhecimento musical cotidiano na educação musical formal a partir da abordagem sócio-histórica. Revista da $A B E M$, Porto Alegre, v. 16, n. 20, p. 35-44, set. 2008.

FRANÇA, C.C. "Uma borboleta nas teclas do piano": significado e desenvolvimento musicais. In: ILARI, B.; BROOCK, A. (orgs.). Música e educação infantil. Campinas: Papirus, 2013. p. 11-36.

MARX, K. Manuscritos econômico-filosóficos. São Paulo: Boitempo, 2010.

PEDERIVA, P. A prática dialogal em educação musical: compreender e criar música na infância. Educação, Batatais, v. 6, n. 2, p. 163-180, jul.-dez. 2016.

PRESTES, Z. Quando não é quase a mesma coisa: traduções de Lev Semionovitch Vigotski no Brasil. Campinas: Autores Associados, 2012.

RAMOS, C.E. de A.S. Ensino-aprendizagem da música da Folia do Divino no litoral paranaense: diálogos entre etnomusicologia e psicologia sócio-histórica a partir do trabalho de campo. Revista da $A B E M$, v. 19, n. 26, p. 158-172, jul.-dez. 2011.

SOUZA, F. de. O brinquedo popular e o ensino de música na escola. Revista da $A B E M$, v. 16, n. 19, p. 75-81, mar. 2008.

VIGOTSKI, Lev S. Psicologia da arte. São Paulo: Martins Fontes, 1998.

VYGOTSKY, Lev. The psychology of art. Cambridge: MIT Press, 1971. Disponível em: <https://www.marxists.org/archive/vygotsky/works/1925/ index.htm>. Acesso em: 12 set. 2017.

\section{NOTAS}

1. Cf., entre outros, Benedetti e Kerr (2008), Souza (2008), Ramos (2011), França (2013).

2. Um exemplo de educadora musical que tem assumido essa concepção é Pederiva (2016).

3. O recorte proposto aqui não me permitirá referir à pedagogia histórico-crítica e às contribuições que traz ao entendimento do lugar da música na formação omnilateral de todos os indivíduos. A quem possa interessar, sugiro a leitura de outros trabalhos meus. Cf. Barbosa (2005; 2007).

4. Cf. Barbosa $(2015 ; 2017)$.

5. Em meus estudos, tomei como fonte principal de consulta o livro Psicologia da arte (VIGOTSKI, 1998), cuja tradução a partir do russo é de Paulo Bezerra; mas quando 
considerei necessário comparei essa versão com a de língua inglesa (VYGOTSKY, 1971) disponível em: <http://www.marxists.org>. Acesso em: 12 set. 2017.

6. Escrito em 1925 e publicado pela primeira vez, por uma editora soviética, em 1965. A essa edição seguiram-se outras corrigidas e ampliadas, pela mesma editora em 1968 e 1986; em 1987, uma nova edição de editora diferente (PRESTES, 2012, p. 118).

7. Esse é também o nome de uma obra de Ludwig van Beethoven, Sonata para violino e piano op. 47, em Lá Maior, que serve de motivo à novela de Tolstói.

8. Na versão inglesa, o termo é "ação futura". Penso que seja mais esclarecedor que "posteriores atitudes".

Recebido em 24 de agosto de 2018.

Aprovado em 11 dezembro de 2018. 